\title{
Review Symposiums
}

Reviews on Eve Darian-Smith, Laws and Societies in Global Contexts: Contemporary Approaches (Cambridge: Cambridge University Press, 2013)

\section{Book Review \\ Spring-boarding into new contexts: reflections on Eve Darian-Smith's Laws and Societies in Global Contexts: Contemporary Approaches}

\author{
Julia Dehm"
}

\section{Introduction}

Readers of Eve Darian-Smith's Laws and Societies in Global Contexts will surely be - as I am - indebted to the remarkable mapping of the field it provides. This book is a rich resource that offers readers not simply a factual training through its content, but also a training in conduct, in ways of seeing, of posing questions and modes of engagement. ${ }^{\mathrm{I}}$ The book operates on a pedagogical register, not just to train us as law and society scholars about our field, but also to train us as socio-legal scholars. Through this training, this book provokes political and ethical scholarly engagement with our deeply unequal and ecologically constrained world.

\section{A training for our times}

The book is a call to scholars of laws and society to challenge their 'taken-for-granted assumptions about what law is, where law appears, and how law works and open up space for fresh thinking about emergent legal practices' (Darian-Smith, 2013, p. 383, emphasis added). In doing so, the book seeks to 'provok(e) further thoughts and imaginings about what law is and what it means to

* Lecturer, La Trobe University School of Law, Australia. E-mail: j.dehm@latrobe.edu.au. These reflections were presented at the 'Anatomy of a Book Session' at the Transnational Law Summer Institute (TLSI) at Kings College, London, in July 20I5. I would like to thank the co-ordinators and organisers of the TLSI Peer Zumbansen and Prabha Kotiswaran for this wonderful opportunity as well as to Helen Bhandari. Many thanks also to Jothie Rajah for conversations about these ideas and to Adil Hasan Khan and Sara Dehm for their perceptive comments on earlier drafts of these reflections.

I In deploying this term, I am indebted to Sundhya Pahuja and Luis Eslava for their work in convening of a recent Colloquium session on 'Mode of Engagement' organised by the Institute for Global Law and Policy at the Harvard Law School, 3-4 June 20I5 (http://iglp.law.harvard.edu/colloquium/). In framing the Colloquium and its objectives, Pahuja and Eslava posed a series of 'how' questions directed to the conduct of the scholar and how we engage with our practice, broadly defined, as both writing, reading, teaching, supervising and critically activism including: How can we think about modes of public engagement, for example, as public intellectuals or activists? How might we enact supervisory relationships which complement our heterodox engagements with global political economy? How may we engage with our research in ways which takes seriously what we know about the production of knowledge? How can we approach the task of writing not only to communicate our concerns, but also as part of the iterative process of thinking? 
whom' (Darian-Smith, 2013, p. 2I, emphasis). The three objectives that Darian-Smith outlines are directed not just towards a field of study, body of literature or object of analysis, but to her audience:

I 'to move sociolegal conversations beyond the taken-for-granted frame of the nation state' (DarianSmith, 2013, pp. 6-7, emphasis added);

2 'to push readers to think more flexibly and critically with respect to the production and meaning of legal knowledge and legal norms at the substate level' (Darian-Smith, 20I3, p. 9, emphasis added);

3 'to demonstrate the necessity to see multiple arenas of legal activity as intrinsically related, mutually constituted, and always in dynamic interaction' (Darian-Smith, 20I3, p. Io, emphasis added).

These verbs are all directed to the readers: we are being 'pushed', our conversations are being 'moved' and it is to us that the necessity of seeing differently is demonstrated, not just in order to teach an argument or a body of literature but also to teach new modes of engagements. This book is in this sense deeply pedagogical, teaching not just scholarship and analytical techniques, but also modes of scholarly practices.

Laws and Societies in Global Contexts adopts the style of a 'text book' and surely will be utilised as such; however, it avoids exhibiting some of the more problematic effects of that genre, namely that of containing or constraining a field of analysis by defining it. The Australian legal scholar Sara Dehm has recently written how "ll]egal textbooks, as "repositories of codified knowledge" ... facilitate the creation and transmission of legal knowledge across time and space, constructing the boundaries of what is considered acceptable and accepted within an interpretative community' (Dehm, 20I5, p. I43). In purporting to define the field, textbooks can also delineate what is excluded from it, relegating certain questions and concerns to outside of the domain of proper knowledge and enquiry within a particular field. Darian-Smith resists these imperatives of disciplinary boundary-marking, specifying that the discussions canvassed and selected texts are 'not intended to be conclusive or definitive in any way', but rather should be viewed as selected 'in the hope of nurturing new conversations, questions, investigations, and research' (Darian-Smith, 20I3, p. 2I). The book therefore does not seek to consolidate or legitimise a domain or a field of enquiry, but rather to operate as a launching pad that is facilitative of further scholarly investigations.

For that reason, I characterise this book as a springboard that provides a basis for new transnational and interdisciplinary modes of enquiry. In this review, I seek to raise some questions that are arguably beyond the scope of this book, but that are provoked by its contents. My questions concern the relationship between law, resistance and social change within a transnational, legal pluralist framework. These questions build on the themes of the book and are inspired by the ethos, normative commitments and deep sense of injustice inherent in the global inequities in the current world order that permeates Laws and Societies in Global Contexts. In many ways, I suggest this is the challenge posed by Darian-Smith to socio-legal scholars: to use the resources collected in this book as the basis for posing the many further questions that our current conjecture demands.

\section{Seeing more critically: choosing to act more critically}

Darian-Smith explicitly raises questions about the production of legal knowledge or 'how we know what we know' and 'how some knowledge becomes more authorative than others' (Darian-Smith, 20I3, p. 97). Inherently linked to this is how the text operates on a pedagogical register to ask scholars to interrogate how they produce specific knowledge of legal phenomena in the way in which they 'frame' a concern. Throughout the book, there is a sometimes explicit, but often more 
implicit, concern with how the relationships between modes of framing, modes of seeing and possibilities of resistance are articulated. Darian-Smith insists that the way we frame a problem matters. The work that a frame does is highlighted in the Kristen Anker text extracted in the book. Anker observes that 'the window's frame, like the frame of a painting, plays a role that is not merely extraneous. It constitutes the object, says what is inside and out, is at once part of the scene while seemingly external to it' (Anker, 2005, in Darian-Smith, 2013, p. I50).

Darian-Smith's call is for a more 'global' or 'transnational' framing of socio-legal problems: that is for scholars to adopt a 'global sociolegal perspective' (Darian-Smith, 20I3, p. I2), through the cultivation of a 'global imaginary' that operates to 'destabaliz(e) our modern and linear understanding of what law is, where law appears, and how law works' (Darian-Smith, 2013, p. I3). She stresses this must be an inclusive frame and that 'all classes and races of people', even those who have never flown overseas, should feature in a global socio-legal perspective (Darian-Smith, 20I3, p. I2).

It is worth recalling critiques from the field of political ecology about the dangers that can be implicit in 'globalist' forms of thinking, and especially how visions of 'one world' globalism can flatten out the heterogeneity of diverse lifeworlds, whilst also justifying the transfer of control and authority from the local to the global level (Sachs, 20Io, p. III). However, Darian-Smith's call can be distinguished from the flattening tendencies of globalist thought in that her argument is not so much about scale, but rather about making visible the connections that extend beyond national boundaries and the transverse diverse sites that produce legal phenomena. Hers is, essentially, a call to not limit a 'global' analysis to a transnational class, but to explore the ways lived grounded experiences in specific places are also part of the ways in which 'law, politics and economic are playing out in a globalizing world' (Darian-Smith, 20I3, p. I2). It is a call for an analysis that is more attentive to the multiplicity of connections that exceed any temporally or geographically bounded frame, in order to better enable socio-legal scholars to see 'links between seemingly unrelated realms that may raise non-intuitive relationships and interconnections' (Darian-Smith, 2013, p. I5). Whilst Darian-Smith's emphasis is on reframing socio-legal issues in order to open up possibilities for seeing and understanding these differently, this analysis can also be extended to highlight how different ways of framing also presents possibilities of imagining praxis and resistance differently.

The possibilities of a more transnationalised framing of issues otherwise understood as 'national' is evident in some of the organising undertaken by the \#BlackLivesMatter movement. The shooting of a young, unarmed Black man, Mike Brown, in Ferguson, Missouri, in August 2014, and the community protest it provoked, has drawn immense national and international attention to the issue of racialised police violence in the US. The events in Ferguson - and the subsequent killings of Eric Garner, Tamir Rice and others - has galvanised a nationwide social movement, \#BlackLivesMatter, challenging the structural nature of racial injustice in the US and the role of law, the prison-industrial complex and racialised policing in its maintenance and reproduction. As mass protests against police brutality and racialised injustice were violently suppressed by in a militarised response in Ferguson and elsewhere, international solidarity manifested itself in concrete ways. On Twitter, under the tagline \#Palestine stands with \#Ferguson, young Palestinians offered strategic advice to protesters in Ferguson on treating pepper spray in messages such as 'always make sure to run against the wind/to keep calm when you're teargassed, the pain will pass, don't rub your eyes!'. While it is important not to undermine the specificity of the US history of slavery and the country's culture of structural racism, activists have shown how a transnationalised framing of Ferguson and its aftermath can also be productive for examining these socio-legal issues differently. For example, a transnationalised framing has highlighted the ways in which the practices of racialised policing, the corporations who are central to the prisonindustrial complex and social justice resistance all exceed the boundaries of the nation state (Ackerman, 2015). Placing these issues within a more global socio-legal context also allows 
examination of both historical struggles by movements to 'internationalize' the question of civil rights, as well as moves by the US to 'domesticate' these issues and to disassociate 'internal' questions of civil rights from struggles for decolonisation and racial justice around the globe (Borstelmann, 2003).

Disrupting frames enables not just different modes of seeing, but also different possibilities for action and new political choices and coalitions. In January 2015, activists from Ferguson, \#BlackLivesMatter, BYP Ioo and Dream defender travelled to Palestine and, subsequently, Patrisse Cullors, co-founder of \#BlackLivesMatter, travelled to the UK to meet with people who had lost family members to police brutality (Hing, 20I5). Emerging from these transnational solidarity tours was a solidarity statement ‘towards liberation' released in August 2015 identifying $\mathrm{G}_{4} \mathrm{~S}$, the world's largest private security company, as a 'target for further joint struggles' (2015 Black Solidarity Statement with Palestine, 20I5). Such engagements position themselves explicitly as part of 'transnational conversations and interactions' intended to 'sharpen' practices of 'joint struggle' (2015 Black Solidarity Statement with Palestine, 2015). These engagements demonstrate the power of situating laws and societies in global contexts not just for scholarly or analytical understandings, but also for the possibilities of political action and the constitution of alternative modes of transnational - or translocal - legalities.

\section{Expanding the scope of socio-legal studies}

The last substantive chapter of the book, 'Re-racializing the world', highlights issues of environmental and racial justice that have been ignored for too long by socio-legal scholars and operates as a call for further scholarship in these areas. In the section on 'environmental apartheid - toxins, floods, diseases', Darian-Smith notes how 'within law and society circles engagement with environmental concerns is virtually absent' (Darian-Smith, 2013, p. 327). She, however, expresses a hope that 'this area of scholarship ... will become important in the sociolegal field' and stresses that 'any serious engagement with the causes and consequences of environmental degradation and climate change will require - at the very least - adopting a global sociolegal perspective' (Darian-Smith, 20I3, p. 328). This call from Darian-Smith is extremely urgent and long overdue. The complexities of the global environmental crisis and the problems of justice, both inter- and intra-generational, that it poses are acute. Moreover, paying attention to the grounded, situated struggles against fossil-fuel extractivism occurring transnationally that Naomi Klein has called 'blockadia' (Klein, 2014, Chapter IO) is not just an imperative for socio-legal scholarship, but also provides a key opportunity for the field. A serious socio-legal analysis of environmental issues requires the 'global' framing this book calls for - an attentiveness to transnational interconnections as well as a sensitivity to legal pluralism and multiple jurisdictional forms. Bringing a socio-legal perspective to bear on questions of environmental justice is not only necessary to address one of the most pertinent issues the world faces, but also that such engagement can productively push socio-legal scholars methodologically in highly intellectually productive ways.

Engaging with environmental justice questions fundamentally requires attention to the 'frictions' (Tsing, 2005) that arise as norms move between 'global' to 'national' and 'local' contexts, as well as the need to disrupt clear delineation between these scales. While environmental justice questions are not unique in propelling the interrogation of the construction of 'local space and subjects that are attuned with global expectations' (Eslava, 2015, p. I0) or how local resistance operates to remake international legal norms (Rajagopal, 2003), they are a productive site for these forms of engagement. The insights that Darian-Smith develops in other chapters of the book urgently need to be developed further within this field, including by exploring 'local conditions of people's experiences and how law is imagined and what law means to individuals and communities in their everyday exchanges' (Darian-Smith, 2013, p. I67). Similarly, Darian-Smith's argument that 'space and its relationship to 
place and time are never to be assumed as given sites of fixed materiality' (Darian-Smith, 20I3, p. I68) offers much to the examination of place-based struggles against transnational supply chains driving unsustainable modes of production. Paying attention to organising across place-based struggles could also help to articulate the way such 'local' struggles can disrupt the securitised logistics of 'global' commodity circulation. Moreover, such a transnational framing of production and circulation provides the basis for a different understanding of what constitutes the 'global'. In this reading, the 'global community' is less the empty political invocation of 'humanity', but rather the patterning of transnational commonality, through the hard work of building meaningful connections and relationships of solidarity between situated struggles.

\section{Laws in contexts: laws in which context?}

The title of the book, in which all nouns are pluralised (Manderson, 20I4), is emblematic of DarianSmith's deep commitment to legal pluralism, evident throughout the text. It is productive to again use this text as a springboard to a broader discussion that remains under-addressed within its pages, namely the ways in which legal plurality can at times operate in ways that are not opposed to, and actually facilitative of, hegemonic systems of control. Contemporary deeply unequal postFordist global capitalism is characterised in part by governance through difference, through forms of 'neoliberal multiculturalism' (Hale, 2005) and by global supply chains in which heterogeneity and gendered or ethnic differences are mobilised and at times play structural or stabilising roles (Tsing, 2009). These tensions are also evident in debates about the new 'green economy' where the question of what impacts carbon sequestration and payment for environmental service schemes often perceived as a form of environmental appropriation or 'green grabbing' (Fairhead et al., 20I2) will have on people living in and around forest areas (Griffiths, 2009). Although fears that people would be dispossessed from their land have been acute (Pearse and Dehm, 20II), at a rhetorical level at least, there has also been a strong focus on the inclusion of indigenous peoples, their knowledges and modes of resource governance into such schemes (Anderson, 20II; Dehm, 20I6).

The North Australian 'West Arnhem Land Fire Abatement Project' has been widely celebrated for its incorporation of indigenous knowledge and scientific research as part of the production of carbon credits under the Carbon Farming Initiative (North Australian Indigenous Land and Sea Management, 'WALFA-West Arnhem Land Fire Abatement project'). Within a 'local' frame, this project can be read as creating space for legal and epistemological pluralism, although still in accordance with the constrained conditions authorised by the settler-colonial state. This reading is, however, complicated when a more transnational framing is adopted that situates this project within a global market for carbon credits and carbon offsets. Such a framing might highlight how this project is funded by ConocoPhillips' to offset liquefied natural gas plant in Darwin Harbour. Further, this framing calls on us to take into account also statements such as that made by Casey Camp-Horinek, a tribal member of the Ponca indigenous nation in the US, who are affected by ConocoPhillips' mining operations in North America, that 'Indigenous Peoples who participate in carbon trading are giving ConocoPhillips a bullet to kill my people' (cited in Goldtooth, 20I0, p. I5). Here, questions of the 'frame' intersect with questions of how the politics of legal pluralism and the complexities of the co-presence of multiple legal systems can be caught between decolonial assertions of autonomy and governance rationalities reminiscent of indirect rule (Li, 20I4). Acknowledging the existence of interlegality as 'fact' does not address the ways in which legal pluralism gets mobilised, by whom and for what purposes. The epistemology and political commitments of this book, I argue, should compel scholars utilising transnational legal pluralist methodologies for socio-legal research to pay further attention to these questions in order to analytically differentiate between conditional forms of legal 
pluralism within polycentric forms of capitalist governance and decolonial forms of decentralised legal pluralism, and to ask who is empowered by and which forms of power are authorised by different forms of legal pluralism.

\section{Legal pluralism as resistance: resistance as legal pluralism}

This book also provides an impetus and a basis for exploring the connections between interlegality as fact and modes of resistance. There is, I suggest, an imperative for socio-legal scholars to examine not just the co-presence of different legalities, but also how the existence of legal pluralism is the product of struggle to maintain, defend or recreate different forms of law. Interlegalities are, so to speak, not just facts that can be naturalised as a given reality, but also in some cases fights that are contingent and dynamic. Such a relationship between resistance and the affirmation of alternative forms of law is articulated in the conclusion to Glen Coulthard's book, Red Skin, White Masks: Rejecting the Colonial Politics of Recognition (Coulthard, 20I4). Coulthard describes blockades - erected by first nations to disrupt the operations of settler-colonialism, extractivism and global capital flows - as both a form of resistance and simultaneously as 'self-affirmative cultural practice that colonised people often critically engage in to empower themselves' (Coulthard, 20I4, p. 23). These blockades are both a point of resistance in that they express a 'no' to the degradation of land and the social worlds it sustains, but, as Coulthard writes, they 'also have ingrained in them a resounding yes: they are the affirmative enactment of another modality of being, a different way of relating to and with the world' and thereby 'become a way of life, another form of community' (Coulthard, 20I4, p. I69). In his discussions, these points of resistance appear concurrently as practices that oppose settlercolonial law, but also authorise the forms of Indigenous law that the blockades are asserting and defending.

\section{Further questions: which laws are authorised in which context}

In the spirit of the pluralisation of all nouns in the title, it seems appropriate to expand upon the questions this book poses and the thematic areas it explores, and the grounding it provides in a field and a mode of socio-legal analysis to springboard into further lines of enquiry. This review has explored how a transnational framing of socio-legal issues can enliven different ways of seeing and acting. It has also posed questions about who authorises and who benefits from acknowledging different forms of legal pluralism. These questions depart from the issues discussed in Laws and Societies in Global Contexts but are both enabled by the framework the book establishes and inspired by the book's normative commitment of striving towards plural forms of global justices (Robinson and Tormey, 2009). It is a testimony to what I have described as the deeply pedagogical character of this book-that it does not just answer questions, but also provokes them, providing fodder for a restless curiosity in a heterogeneous, densely layered and contradiction-ridden socio-legal world.

\section{References}

'2015 BLACK SOlidarity STATEMENT With PAlestine' (20I5) Available at: <http://www.blackforpalestine. $\mathrm{com} /$ read-the-statement.html> (accessed 23 October 2017).

ACKerman, Spencer (2015) 'Bad Lieutenant: American Police Brutality, Exported from Chicago to Guantànamo', The Guardian, I8 February 2015. Available at: 〈http://www.theguardian.com/usnews/20I5/feb/I8/american-police-brutality-chicago-guantanamo〉 (accessed 23 October 2017).

ANDERson, Patrick (20I I) Free, Prior, and Informed Consent in REDD+: Principles and Approches for Policy and Project Development. Bangkok: RECOFTC (The Centre for People and Forests) and GIZ. 
AnKer, Kristen (2005) 'The Truth in Painting: Cultural Artifacts as Proof of Native Title', 9 Law, Text, Culture in Eve Darian-Smith (ed.) (2013) Laws and Societies in Global Contexts: Contemporary Approaches. Cambridge, UK: Cambridge University Press, 9I-I 24.

Borstelmann, Thomas (2003) The Cold War and the Color Line: American Race Relations in the Global Era.

Cambridge, MA: Harvard University Press.

Coulthard, Glen Sean (2014) Red Skin, White Masks: Rejecting the Colonial Politics of Recongition. Minneapolis: University of Minnesota Press.

DARIAN-SMith, Eve (2013) Laws and Societies in Global Contexts: Contemporary Approaches. Cambridge,

UK: Cambridge University Press.

DEHM, Julia (20I6) 'Indigenous Peoples and REDD+ Safeguards: Rights as Resistance or Disciplinary

Inclusion in the Green Economy?', Journal of Human Rights and the Environment 7(2): I70-2 I 7.

DEHM, Sara (20I5) 'Framing International Migration', London Review of International Law 3(I): I33-I68. ESLAVA, Luis (2015) Local Space, Global Life: The Everyday Operation of International Law and Development.

Cambridge, UK: Cambridge University Press.

faIRHEAd, James, LEACH, Melissa and scoones, Ian (2012) 'Green Grabbing: A New Appropriation of Nature?', Journal of Peasant Studies 39(2): 237-26I.

Goldtooth, Tom B. K. (20I0) 'Why REDD/REDD+ Is Not a Solution' in Joanna Cabello and

Tamra Gilbertson (eds) No REDD+ A Reader. Hermosillo, Sonora: Carbon Trade Watch and Indigenous Environment Network.

GRIFFITHS, Tom (2009) Seeing 'REDD'? Forests, Climate Change Mitigation and the Rights of Indigenous

Peoples: Updated Version. Moreton-in-Marsh: Forest Peoples' Programme.

Hale, Charles R (2005) 'Neoliberal Multiculturalism: The Remaking of Cultural Rights and Racial

Dominance in Central America', PoLAR 28(I): 10-28.

HING, Julianne (2015) “Black Lives Matter Goes International', ColourLines, 30 January 20I5. Available at:

$\langle$ http://www.colorlines.com/articles/black-lives-matter-goes-international〉 (accessed 23 October 2017).

KLeIN, Naomi (2014) This Changes Everything: Capitalism vs. the Climate. New York: Simon \& Schuster.

LI, Tania Murray (20I4) 'Fixing Non-Market Subjects: Governing Land and Population in the Global

South', Foucault Studies I 8: 34-48.

MANDERSON, Desmond (20I4) 'AD 20I4: A Review of Eve Darian-Smith, Laws and Societies in Global

Contexts-Contemporary Approaches', Law and Humanities 8(I): 77-87.

NORTH AUSTRALIAN INDIGENOUS LAND AND SEA MANAGEMENT, 'WALFA-West Arnhem Land Fire Abatement

project'. Available at: 〈https://www.nailsma.org.au/walfa-west-arnhem-land-fire-abatement-

projecthtml.html> (accessed I5 November 2017).

PEARSE, Rebecca and DEHM, Julia (20II) In the REDD: Australia's Carbon Offset Project in Central

Kalimantan. Amsterdam: Friends of the Earth International.

RAJAGOPAL, Balakrishnan (2003) International Law from Below: Development, Social Movements and Third

World Resistance. Cambridge, UK: Cambridge University Press.

Robinson, Andrew and tormey, Simon (2009) 'Resisting "Global Justice": Disrupting the Colonial

"Emancipatory" Logic of the West', Third World Quarterly 30(8): I395-I409.

sachs, Wolfgang (2010) 'One World' in Wolfgang Sachs (ed.) The Development Dictionary: A Guide to

Knowledge as Power, 2nd edn. London and New York: Zed Books, I I I-I 26.

TSING, Anna (2009) 'Supply Chains and the Human Condition', Rethinking Marxism: A Journal of

Economics, Culture \& Society $2 \mathrm{I}(2)$ : I 48-I 76.

TSING, Anna Lowenhaupt (2005) Friction: An Ethnography of Global Connection. Princeton: Princeton

University Press. 